\title{
Qualidade e estilo de vida de produtores de leite em propriedades rurais de um município do Cone Sul de Rondônia
}

\section{Quality and style of life of dairy farmers in rural properties of a city in the Southern Cone of Rondônia}

\author{
1 Wellington Nascimento Moura wellingtonedfisica@hotmail.com \\ 2 Claudete Rempel \\ 2 Lydia Christmann Espindola Koetz
}

1 Faculdade de Educação e Cultura de Vilhena
2 Universidade do Vale do Taquari - Univates

\section{Resumo}

O objetivo do estudo é analisar a percepção de produtores de leite do município de Vilhena, situado no Cone Sul de Rondônia, sobre qualidade e estilo de vida. A pesquisa, com perfil quali-quantitativo e de corte transversal foi realizada com 42 produtores de leite (19 mulheres e 23 homens). Foi avaliada a qualidade de vida, com a utilização do instrumento WHOQOL-BREF e o estilo de vida, com a utilização do questionário do pentáculo do bem-estar. A média dos escores de qualidade de vida no domínio físico foi de 54,9 $\pm 12,3$; domínio psicológico, $62,5 \pm 17,5$; domínio social, $59,3 \pm 19,1$; domínio ambiental, $55,1 \pm 14,3$. Já os cinco componentes do estilo de vida tiveram os seguintes escores: alimentação 1,5 \pm 05 ; atividade física 2,1 $\pm 0,7$; comportamento preventivo $1,8 \pm 0,5$; relacionamentos $1,9 \pm 0,6$; controle do estresse $1,8 \pm 0,6$. Há correlação forte, positiva e significativa entre a qualidade de vida e o estilo de vida dos participantes da pesquisa $(r=$ 0,$73 ; p<0,0001$ ). É possível inferir que $53 \%$ do estilo de vida determina a qualidade de vida. Não há diferença estatística significativa no estilo de vida de homens e mulheres produtoras rurais $(t=0,57 ; p=0,57$ ) e também não há diferença na qualidade de vida de homens e mulheres produtoras $(t=-0,22 ; p=0,83)$. A maioria dos produtores (67\%) considera sua qualidade de vida "nem ruim nem boa" nos aspectos físico e ambiental. Já quanto ao estilo de vida, o componente "alimentação" apresentou os menores escores.

Palavras-chave:

Comportamentos relacionados à saúde. Conduta de saúde. Qualidade de vida relacionada à saúde.

\begin{abstract}
The objective of the study is to analyze the perception of milk producers in the municipality of Vilhena, located in the Southern Cone of Rondônia, about quality of life and lifestyle. The research, with a qualitative and quantitative cross-sectional profile, was performed with 42 milk producers (19 women and 23 men). Quality of life was assessed using the WHOQOL-BREF instrument and lifestyle using the pentacle of well-being questionnaire. The mean quality of life scores in the physical domain was $54.9 \pm 12.3$; psychological domain $62.5 \pm 17.5$; social domain $59.3 \pm 19.1$; environmental domain $55.1 \pm 14.3$. The five components of lifestyle had the following scores: feeding $1.5 \pm 05$; physical activity 2.1 \pm 0.7 ; preventive behavior $1.8 \pm 0.5$; relationships $1.9 \pm$ 0.6 ; stress control $1.8 \pm 0.6$. There is a strong, positive and significant correlation between the quality of life and the lifestyle of the research participants $(r=0.73, p$ $<0.0001$ ). It is possible to infer that $53 \%$ of the lifestyle determines the quality of life. There was no statistically significant difference in the lifestyle of rural women and men ( $t=0.57, p=0.57$ ) and there was no difference in the quality of life of men and women producers ( $t=$ -0.22; $p=0.83)$. Most producers $(67 \%)$ consider their quality of life "neither bad nor good" in physical and environmental aspects. Regarding lifestyle, the "food" component had the lowest scores.
\end{abstract}

\section{Keywords:}

Health-related behaviors. Health Conduct. Quality of Life Related to Health.

\section{Como você deve citar?}

MOURA, Wellington Nascimento; REMPEL, Claudete; KOETZ, Lydia Christmann Espindola. Qualidade e estilo de vida de produtores de leite em propriedades rurais de um município do Cone Sul de Rondônia. Cadernos UniFOA, Volta Redonda, n. 40, p. 127-137, agosto 2019. 
Qualidade e estilo de vida de produtores de leite em propriedades rurais

de um município do Cone Sul de Rondônia

\section{INTRODUÇÃO}

A agroindústria surgiu no Brasil em meados dos anos 70 , período em que teve início a industrialização de animais (gado e suínos) e de alimentos como café, laranja, soja e cana-de-açúcar, que eram os principais produtos comercializados na época. Após ocorrer a fusão entre agropecuária e indústria, o país se desenvolveu tecnicamente e se destaca no mundo do agronegócio.

O agronegócio é o conjunto dos segmentos de insumos para a agropecuária, para a produção básica, para a agroindústria e para o agrosserviço, integrando diversos setores da economia brasileira. 0 setor representa um terço do Produto Interno Bruto (PIB), o que evidencia sua importância econômica e social no mercado brasileiro, estando diretamente ligado à geração de emprego e renda nos municípios.

A cadeia produtiva do leite, no Brasil, é de grande importância no agronegócio nacional, atuando nos segmentos de produção, industrialização e comercialização de leite e derivados em todas as regiões do território nacional. Sendo assim, esse setor também desempenha um papel relevante no suprimento de alimentos e na geração de emprego e renda para a população (COSTA, 2009).

O desenvolvimento da indústria de lacticínios no país iniciou em meados do século $X X$, mais especificamente em 1940, quando o Governo começou a intervir nos preços e a regulamentar a atividade leiteira, visando garantir ao consumidor o acesso a produtos seguros, sem risco de contaminação (CÔNSOLI; FAVA NEVES, 2006 apud SCHEIDT, 2008). A partir de então, a pecuária leiteira nacional passou por transformações importantes. Uma delas foi a entrada do produto "leite longa vida" (UTH - Ultra High Temperature) no mercado, que ocorreu a partir de 1980. Com isso, a produção leitura cresceu de forma considerável, passando de 14,4 bilhões, em 1990, para 27,5 bilhões, em 2010 (CARVALHO, 2011).

Nesse contexto, segundo Nero, Viçosa e Pereira (2009), a produção de leite tornou-se uma atividade economicamente importante para o país, praticada principalmente por pequenos produtores. Essa atividade produtiva tem favorecido o setor agropecuário, visto que contribui no estabelecimento de mais renda e empregos aos produtores e, por consequência, garantindo-Ihes a estabilidade no campo (CAMPOS; PIACENTI, 2007).

No ranking nacional dos maiores Estados produtores de leite, Rondônia encontra-se numa posição privilegiada, ocupando o $9^{\circ}$ lugar, com aproximadamente 35 mil pequenos e médios produtores rurais, gerando emprego e renda nas áreas rurais e nos perímetros urbanos (OLIVEIRA, 2016). 0 estado perde apenas para gigantes tradicionais no setor, como Minas Gerais, Rio Grande do Sul, Paraná, Goiás, Santa Catarina, São Paulo, Bahia e Pernambuco, mas está à frente de Mato Grosso, Pará e Mato Grosso do Sul (OLIVEIRA, 2016).

De acordo com levantamentos da Secretaria de Agricultura, Rondônia tem uma produção média acima de 2,2 milhões de litros de leite/dia, sendo considerado o maior Estado produtor de lácteos da região Norte. A região denominada Cone Sul, em Rondônia, é formada por sete municípios, que se destacam na produção leiteira, sendo Vilhena, o maior produtor (SEBRAE, 2015).

Convém referir que os períodos de chuva e seca impactam sobre a produção de leite na região. No período de chuvas, a produção atinge 2,6 milhões de litros/dia, ao passo que, na época da seca, são produzidos 1,9 milhão de litros/dia (SEBRAE, 2015).

0 trabalho dos produtores leiteiros envolve diversas tarefas, como: manejo dos animais (alimentação e tratamento); ordenha (preparação do animal, ordenha propriamente dita e armazenamento do leite); higienização do ambiente e do material, isolamento do produto lácteo em tanques de resfriamento, entre outros. Com transformações constantes no meio rural, pequenos agricultores buscam, mesmo 
com pouco capital, investir em melhores condições de realizar seu trabalho, proporcionando um aumento na qualidade de vida; contudo, ainda existem produtores que executam suas tarefas de forma rudimentar, ignorando a utilização de equipamentos tecnológicos que poderiam auxiliar e aumentar a produtividade, bem como melhorar a qualidade de vida (COSTA et al., 2011)

O conceito de qualidade de vida (QV) emergiu a partir de interesses de cientistas sociais, filósofos e políticos. Conforme a Organização Mundial da Saúde - OMS (1998), a QV reflete a percepção dos indivíduos acerca da satisfação de suas necessidades, ou ainda, que lhes estão sendo negadas oportunidades de alcançar a felicidade e a autorrealização, com independência de seu estado de saúde físico ou das condições sociais e econômicas. Nessa perspectiva, houve um movimento epistemológico dentro das ciências humanas e biológicas que objetivou valorizar questões mais amplas, indo além do controle de sintomas, da diminuição da mortalidade ou do aumento da expectativa de vida (OMS, 1998).

Nahas (2017) entende a QV como a medida individual da percepção dos sujeitos, relacionada à própria dignidade humana, o que parece totalmente humanista, para considerar a QV como a percepção de bem-estar resultante de um conjunto de parâmetros individuais e socioambientais modificáveis ou não que caracterizam condições em que vive o ser humano. Entre os parâmetros individuais, está a hereditariedade e o estilo de vida (hábitos alimentares, controle do estresse, atividade física habitual, comportamento preventivo, relacionamentos); já entre os parâmetros socioambientais, está a moradia, o transporte, a segurança, a assistência médica, a educação, a cultura e o meio ambiente.

Diante do exposto, este trabalho tem como objetivo avaliar a percepção de produtores de leite do município de Vilhena, no Cone Sul de Rondônia, sobre sua qualidade e estilo de vida.

\section{MÉTODO}

A pesquisa foi realizada com 42 produtores de leite do município de Vilhena associados da Cooaprovir - Cooperativa Agropecuária de Produtores de Leite de Vilhena. A cidade está localizada na porção sul-leste do Estado de Rondônia, com uma população estimada em 98 mil habitantes, sendo o quarto município mais populoso do estado. Além disso, apresenta o segundo melhor IDH de Rondônia. Diversos setores da cidade estão em franco desenvolvimento, mas destaca-se o fortalecimento agrícola. No setor de pecuária leiteira, o município apresenta cerca de 180 produtores que trabalham com, aproximadamente, 2.060 animais.

A Cooaprovir conta com 105 associados. Foram selecionados $40 \%$ destes (42 propriedades) para compor a amostra desta pesquisa. As visitas foram orientadas por um técnico da EMATER/RO que auxiliou na localização das propriedades ativas com produção de leite. As entrevistas foram realizadas com os responsáveis pela ordenha ou ajudantes e/ou pela manutenção econômica da família, independente do gênero.

Foi agendado horário com o produtor que compareceu na reunião de cooperados, para que o pesquisador pudesse visitá-lo em sua propriedade e, posteriormente, para a realização da entrevista semiestruturada. Com a entrevista, foi traçado o perfil dos produtores, bem como identificada a percepção deles sobre qualidade vida e o seu estilo de vida. O referido instrumento de coleta buscou dados socioeconômicos do produtor, sua escolaridade, estrutura familiar, presença de doenças crônicas, bem como sua percepção sobre QV e fatores que interfiram na QV.

Durante as entrevistas, foi solicitado que os produtores entrevistados preenchessem os dois questionários para avaliação da QV. O primeiro questionário foi elaborado a partir das ideias Nahas (2017), intitulado modelo do Pentáculo do Bem-estar, que envolve os cinco fatores fundamentais para 
Qualidade e estilo de vida de produtores de leite em propriedades rurais de um município do Cone Sul de Rondônia

o estilo de vida das pessoas: nutrição, atividade física, controle do estresse, relacionamento social e comportamento preventivo. Ao todo, são quinze itens a serem respondidos, com uma escala que varia de zero (0) a três (3) pontos, onde o zero (0) representa ausência total de tal característica no estilo de vida; um (1), às vezes; dois (2), quase sempre; e três (3) representa a completa realização do comportamento citado. Ao final, somam-se os pontos atribuídos a cada questão e quanto maior a pontuação, melhor o estilo de vida do produtor.

Para a avaliação da qualidade de vida, foi aplicado o WHOQOL-BREF, em que são investigados quatro domínios: físico, psicológico, ambiental e relações sociais. A análise dos dados foi feita conforme sintaxe prevista pelo WHOQOL GROUP - World Health Organization Quality of Life (FLECK, 2000). 0 instrumento WHOQOL-BREF foi abreviado do instrumento WHOQOL-100, sendo validado nacionalmente pelo departamento de Psiquiatria e Saúde Comportamental da UFRGS, coordenado pelo Dr. Marcelo Pio de Almeida Fleck. É um instrumento com questões simples e linguagem autoaplicável e acessível. Possui a vantagem de apresentar caráter transcultural e internacional, podendo ser inserido facilmente em diversas áreas da saúde e fornecendo informações necessárias, a fım de se realizar intervenções no âmbito da QV.

O questionário WHOQOL-BREF está organizado em 26 questões: duas estão direcionadas à qualidade de vida; sete envolvem o domínio físico, isto é, exploram as condições físicas no desenvolvimento do trabalho e no cotidiano (dor e desconforto, energia e fadiga, sono e repouso, mobilidade, atividades da vida cotidiana, dependência de medicação ou tratamentos e capacidade de trabalho); seis questões tratam do domínio psicológico, envolvendo o parâmetro emocional, que abrange os sentimentos positivos, pensar, aprender, memória, concentração, imagem corporal e aparência, sentimentos negativos e crenças pessoais; três questões envolvem o domínio das relações sociais, que analisa as relações pessoais em grupo e individual (relações pessoais, suporte social e atividade sexual); e, por fim, oito questões abarcam o domínio ambiental, em que é analisada a relação do indivíduo com o meio de forma individual e na sua totalidade, abordando aspectos ligados à segurança física, aos recursos financeiros, aos cuidados de saúde, à disponibilidade social, à participação e oportunidade de recreação e lazer, à qualidade do ambiente físico (poluição, ruído, trânsito e clima) e ao transporte (FLECK, 2000).

Para identificação dos aspectos da QV que podem ser melhorados, os dados foram caracterizados qualitativamente, de acordo com metodologia proposta por Padrão e Sens (2009), sendo considerada a QV "muito ruim" escores de 0-20; "ruim", de 21-40; "nem ruim nem boa", de 41-60; "boa", de 61-80 e "muito boa" de 80-100.

Os dados foram analisados e mensurados após a aplicação dos instrumentos questionáveis com os produtores de leite, seguindo o padrão avaliativo já estabelecido nos dois questionários utilizados. As variáveis resultantes do questionário WHOQOL-BREF foram organizadas em gráficos que demonstram as respostas informadas pelo participante. O Pentáculo do Bem-estar será apresentado a partir dos resultados obtidos pela indicação das escalas de 0 a 3 .

Para comparar o estilo de vida e a qualidade de vida de homens e mulheres, utilizou-se o teste t. Para a comparação das diferenças entre os componentes do estilo de vida foi realizada a prova não paramétrica de Friedman. Para a avaliação da associação entre a qualidade de vida e o estilo de vida, foi realizada a correlação de Pearson. Foram consideradas significativas diferenças $p<0,05$.

O presente estudo foi submetido ao Comitê de Ética em Pesquisa da Univates, seguindo as diretrizes da Resolução n 466, de 12 de dezembro de 2012, do Conselho Nacional de Saúde, sendo aprovado e, em seguida, iniciado a aplicação dos questionários e consequentes coletas de dados (Parecer 2.911.708). O Termo de Consentimento Livre e Esclarecido (TCLE) foi lido e assinado pelos participantes da pesquisa. 


\section{RESULTADOS E DISCUSSÃO}

$\mathrm{Na}$ área rural de Vilhena, foram entrevistados 42 produtores de leite, no período de setembro a novembro de 2018 , sendo que, desse total, 23 trabalhadores são homens com idades que vão dos 33 até 65 anos e as mulheres perfazem um total de 19 trabalhadoras que apresentam idades entre 28 a 67 anos.

Na figura 1 é apresentado o perfil do estilo de vida por sexo, demonstrando que $26,3 \%$ de mulheres e $26,1 \%$ de homens apresentam-se insatisfeitos com o seu estilo de vida.

Figura 1 - Perfil do Estilo de vida, por sexo, dos produtores rurais

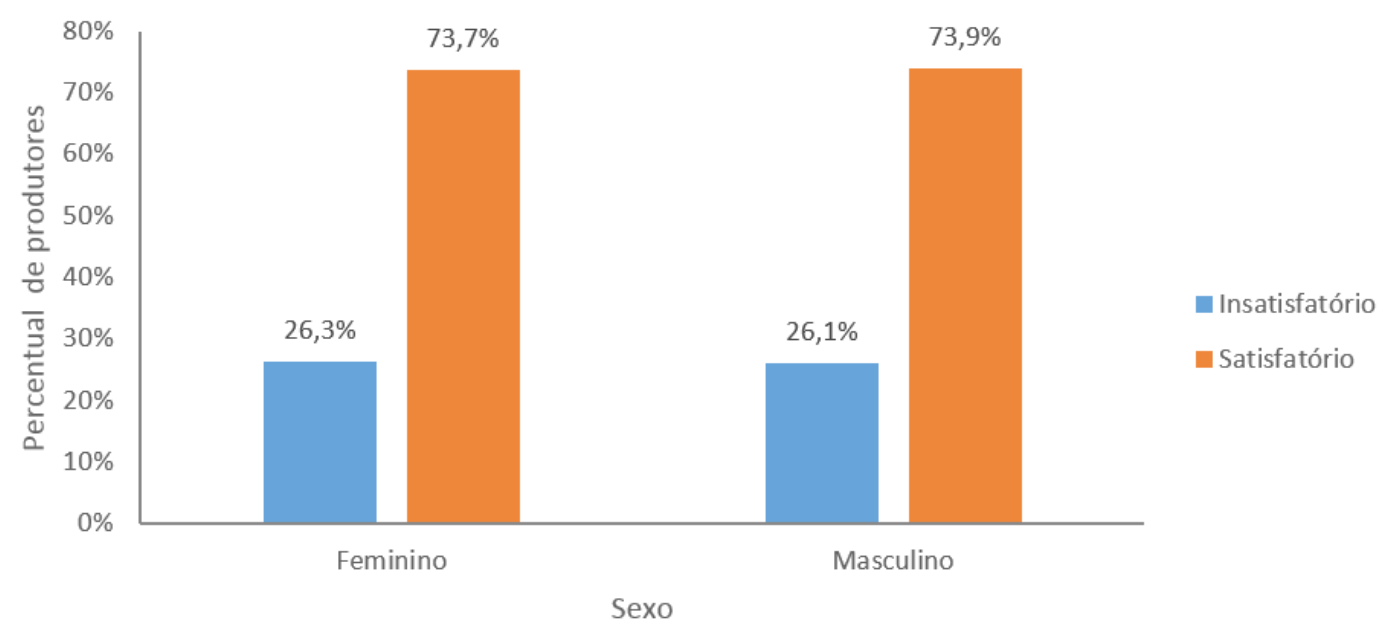

Fonte: Dados da pesquisa (2018)

O questionário do Pentáculo do Estilo de Vida é organizado dentro de cinco componentes com agrupamento de três perguntas em cada um, para que, assim, se possa analisar o estilo de vida do indivíduo e/ou grupo estudado. Os componentes são alimentação, atividade física, comportamento preventivo, relacionamentos e controle do estresse e, para cada componente, há uma variação de pontos de 0 a 3 , conforme atribuições dadas a cada pergunta respondida do questionário pelo indivíduo pesquisado.

Os índices apresentados na figura 2 apresentam um dos componentes com maior preocupação, 0 componente Nutrição/Alimentação, já que ambos os sexos apresentaram tendência de comportamento negativo, quando se refere a sua rotina de alimentação com inclusão de frutas, legumes, verduras e também a não realização de, pelo menos, 5 refeições/dia e a não ingestão de gorduras e açucares.

Para Nahas (2017), o que você come e o que se faz tem impacto direto na saúde. A melhor maneira de assegurar uma dieta saudável é incluir uma ampla variedade de alimentos nas refeições diárias. Existe uma relação entre o estado nutricional do trabalhador e sua capacidade de produção, sendo que qualquer deficiência acentuada em termos de proteínas e/ou calorias pode provocar uma redução na força muscular, na eficiência dos movimentos e no rendimento do trabalho (SCARPARO; AMARO; OLIVEIRA 2010).

O componente "atividade física" foi o mais significativo, tanto para os homens quanto para as muIheres entrevistadas, pois, apesar da rotina diária de trabalho dos produtores de leite, há uma tendência a um comportamento positivo, sendo que as atividades diárias já representam as características avaliativas desse componente no questionário, como caminhada, andar de bicicleta e exercícios que 
exijam força. Nahas (2017) registra que os hábitos são formados pela repetição de certos comportamentos (ações do cotidiano).

Figura 2 - Média da avaliação dos componentes do estilo de vida, por sexo, dos produtores rurais

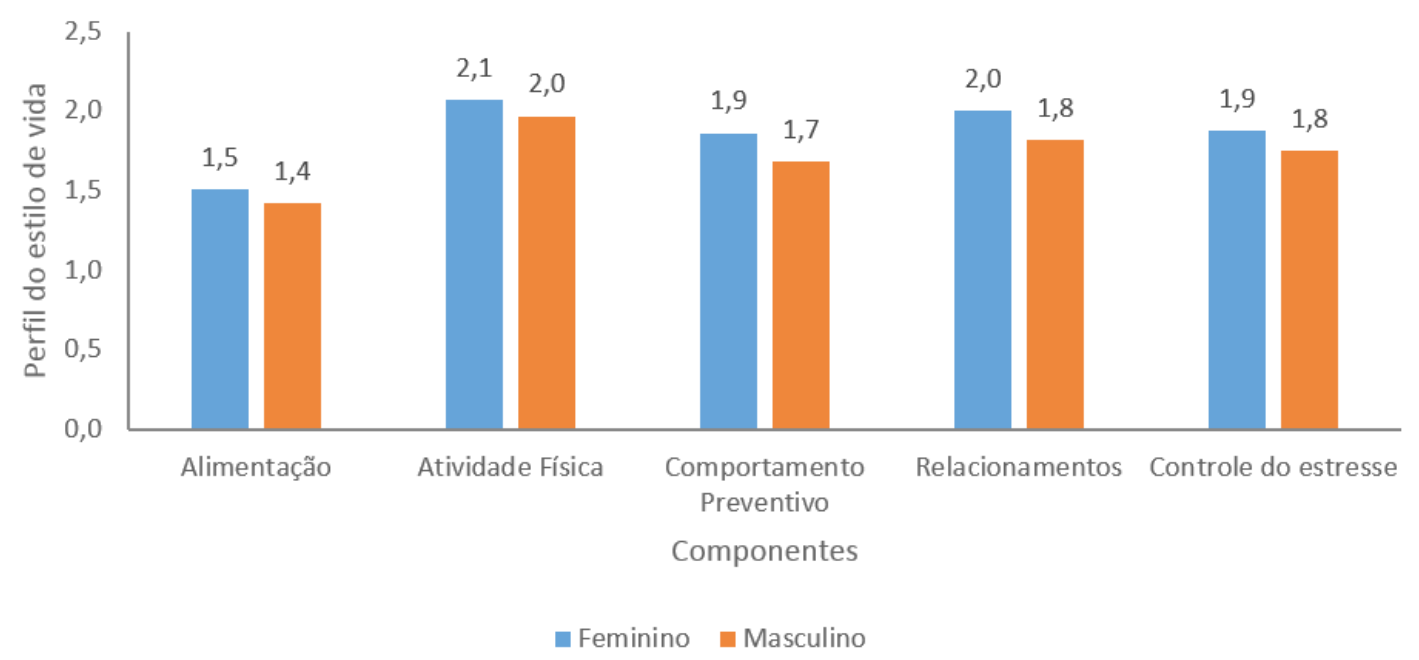

Fonte: Dados da pesquisa (2018)

A preocupação com cuidados relacionados à pressão arterial, colesterol controlado, uso do álcool, cigarros e segurança no transito são características do componente comportamento preventivo. Foi demonstrado por ambos os gêneros entrevistados uma tendência de comportamento negativo. No componente relacionamentos, na análise das trabalhadoras do sexo feminino, foi demonstrada uma tendência ao comportamento positivo, pois as participantes relatam como rotina reunião com amigos e participação em associações. Já os trabalhadores do sexo masculino apresentaram uma tendência a um comportamento negativo.

Sharkey (1980) relata que pesquisadores da Califórnia listaram vários hábitos, sendo que a abstinência de cigarros e drogas e uso moderado (ou abstinência) de álcool poderiam adicionar 11 anos de vida aos homens e 7 anos às mulheres, simplesmente seguindo os hábitos.

Já no componente controle do estresse, ambos os sexos demonstraram tendência a um comportamento negativo, caracterizado por passar mais tempo trabalhando, não parar para relaxar e se manter alterado em uma discussão.

O Pentáculo do Bem-estar é uma representação gráfica com as variáveis estabelecidas pelos cinco componentes do questionário Perfil do Estilo de Vida de um indivíduo ou grupo em estudo. A figura 3 apresenta os resultados obtidos do estilo de vida dos trabalhadores rurais produtores de leite em estudo na pesquisa. Os resultados incluem as características nutricionais, nível de estresse, atividade física habitual, relacionamento social e comportamentos preventivos, com intuito de facilitar a visualização dos segmentos abordados (NAHAS, 2017). 
Wellington Nascimento Moura / Claudete Rempel Lydia Christmann Espindola Koetz

Figura 3 - Pentáculo do Bem-estar para os produtores rurais participantes da pesquisa

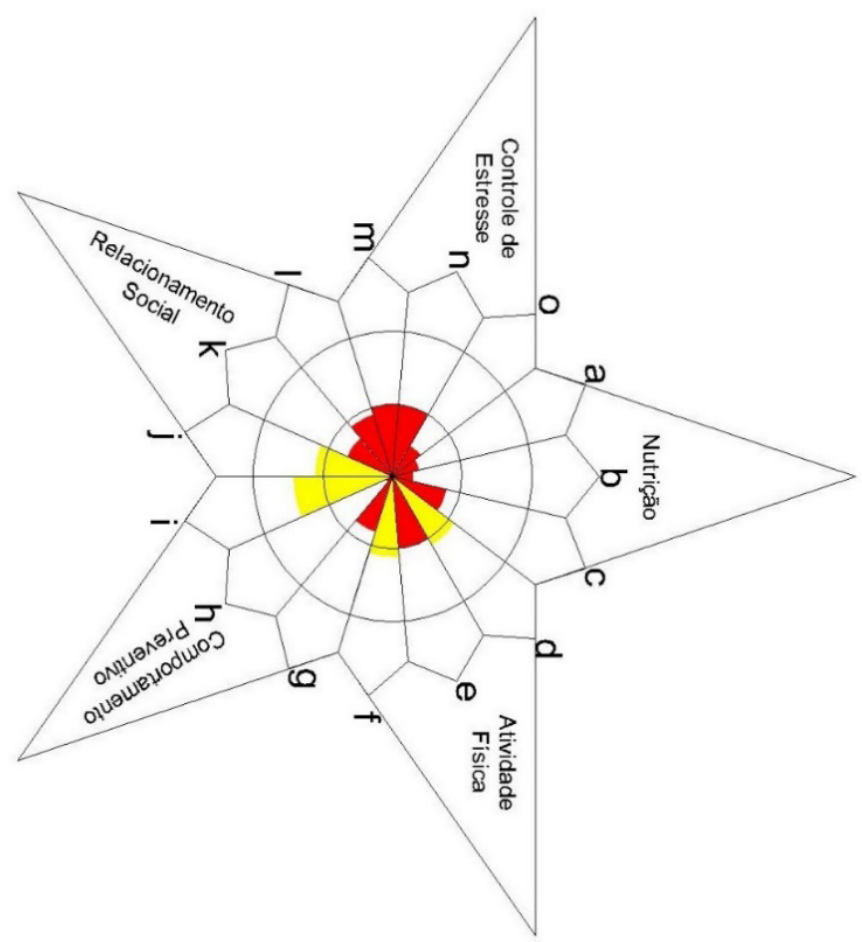

Fonte: Dados da pesquisa (2018)

A figura 4 apresenta as médias do estilo de vida dos produtores rurais participantes da pesquisa. Percebe-se que a atividade física é a que apresentou os melhores escores, enquanto que o componente "alimentação" diferiu estatisticamente dos demais e apresentou os menores escores.

Figura 4 - Comparação das médias dos componentes do estilo de vida dos produtores rurais.

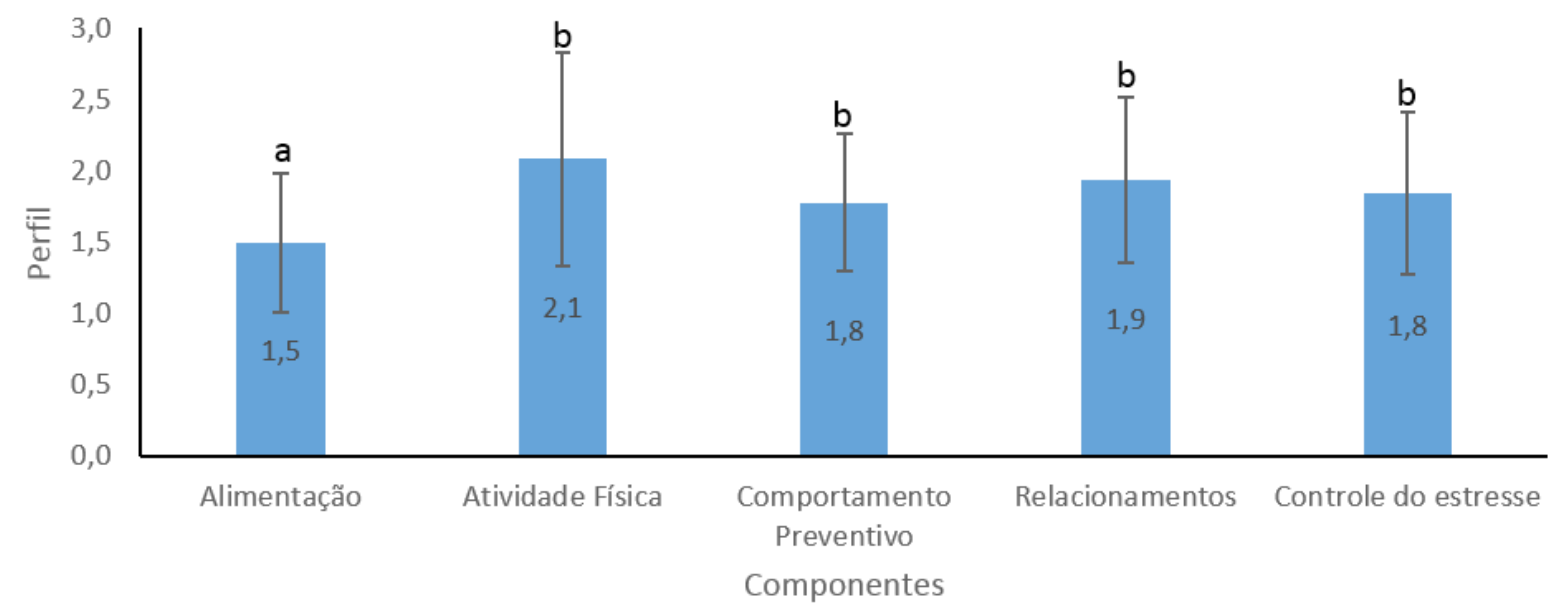

* Letras diferentes diferem entre si $(p<0,05)$

Fonte: Dados da pesquisa (2018)

Há correlação forte, positiva e significativa entre a qualidade de vida e o estilo de vida dos participantes da pesquisa $(r=0,73 ; p<0,0001)$. É possível inferir que $53 \%$ do estilo de vida determina a qualidade de vida, conforme pode ser visualizado na figura 5. 
Figura 5 - Correlação entre a qualidade de vida e o estilo de vida dos produtores rurais

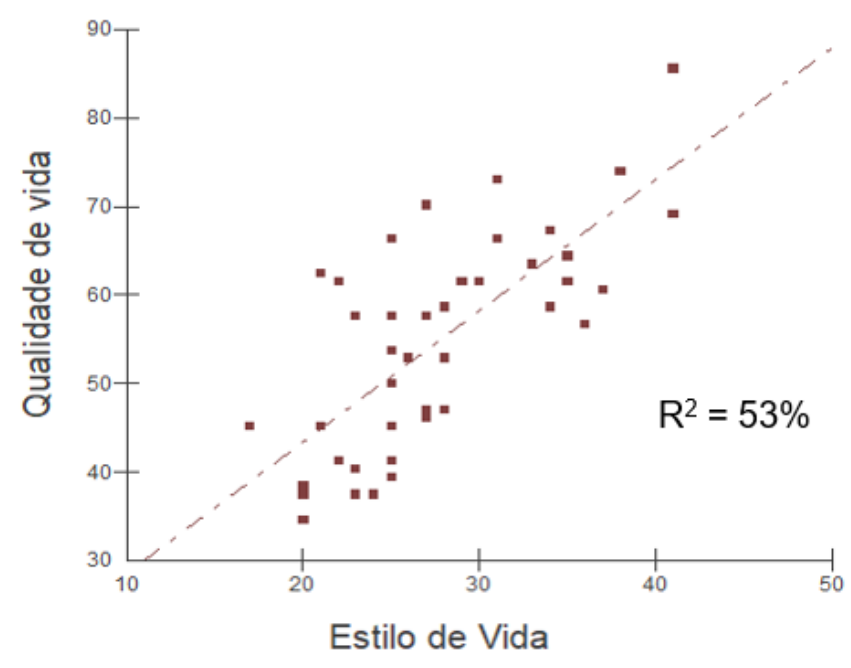

Fonte: Dados da pesquisa (2018)

As variáveis para avaliação da QV do WHOQOL-BREF foram os quatro domínios: físico (dor e desconforto; energia e fadiga; sono e repouso; atividades da vida cotidiana; dependência de medicação ou tratamentos e capacidade de trabalho); psicológico (sentimentos positivos; pensar, aprender, memória e concentração; autoestima; imagem corporal e aparências; sentimentos negativos; espiritualidade, religiosidade e crenças pessoais); relações sociais (relações pessoais; suporte social e atividade sexual); meio ambiente (segurança física e proteção; ambiente no lar; recursos financeiros; cuidados de saúde e sociais; disponibilidade e qualidade; oportunidade de adquirir novas informações e habilidades; participação e oportunidade de recreação/lazer; ambiente físico: poluição, ruído, trânsito, clima e transporte) (FLECK et al., 2000). A figura 6 apresenta a média e o desvio-padrão de cada um dos domínios avaliados. Percebe-se que os melhores escores foram do domínio psicológico e os piores do domínio físico.

Figura 6 - Média e desvio-padrão dos escores de qualidade de vida dos produtores rurais participantes da pesquisa

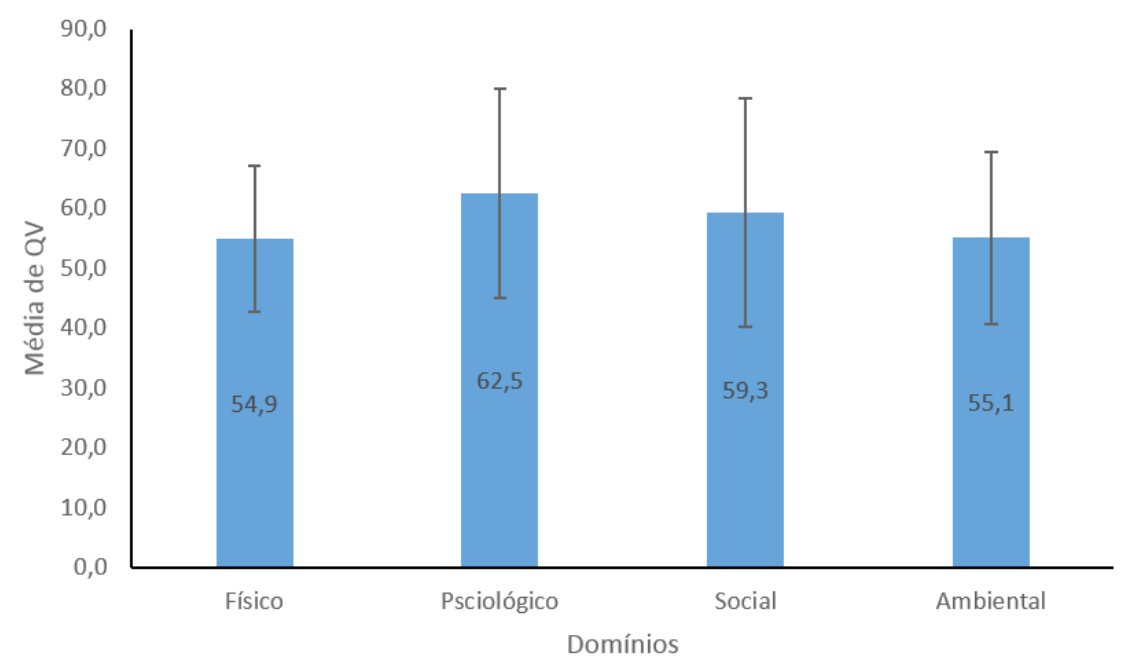

* Não há diferença estatística significativa na qualidade de vida nos diferentes escores Fonte: Dados da pesquisa (2018) 
Observando-se os resultados na figura 6, pode-se inferir que, de forma geral, os domínios do WHOQOL-BREF apresentaram escores médios classificados, de acordo com Padrão e Sens (2009) como "nem ruim e nem bom". Apenas no aspecto psicológico a QV dos produtores pode ser classificada como "boa". Essa tendência pode ser verificada em outros estudos, como o de Timossi (2009).

Em um estudo realizado também com produtores rurais do Vale do Taquari/RS, os escores médios de qualidade de vida são superiores aos encontrados no presente trabalho em todos os domínios (74 no físico, 72 no psicológico, 86 no social e 77 no ambiental (MORÁS et al., 2018). Essa diferença é algo que precisa ser investigado, para se compreender o que faz com que os produtores do Sul tenham uma melhor percepção da sua qualidade de vida.

A figura 7 permite a visualização da distribuição dos escores de qualidade de vida dos produtores rurais de ambos os sexos nos quatro domínios analisados. No domínio físico, houve um percentual de $74 \%$ de insatisfação, sendo que $7 \%$ acha sua QV "ruim"; $67 \%$, "nem ruim e nem boa"; e $26 \%$ acha que sua qualidade de vida é "boa", sendo que esse item relacionado à saúde física e mental, autoconhecimento e estar ativo.

Figura 7 - Percentual de distribuição dos escores de QV dos produtores rurais de acordo com os domínios analisados

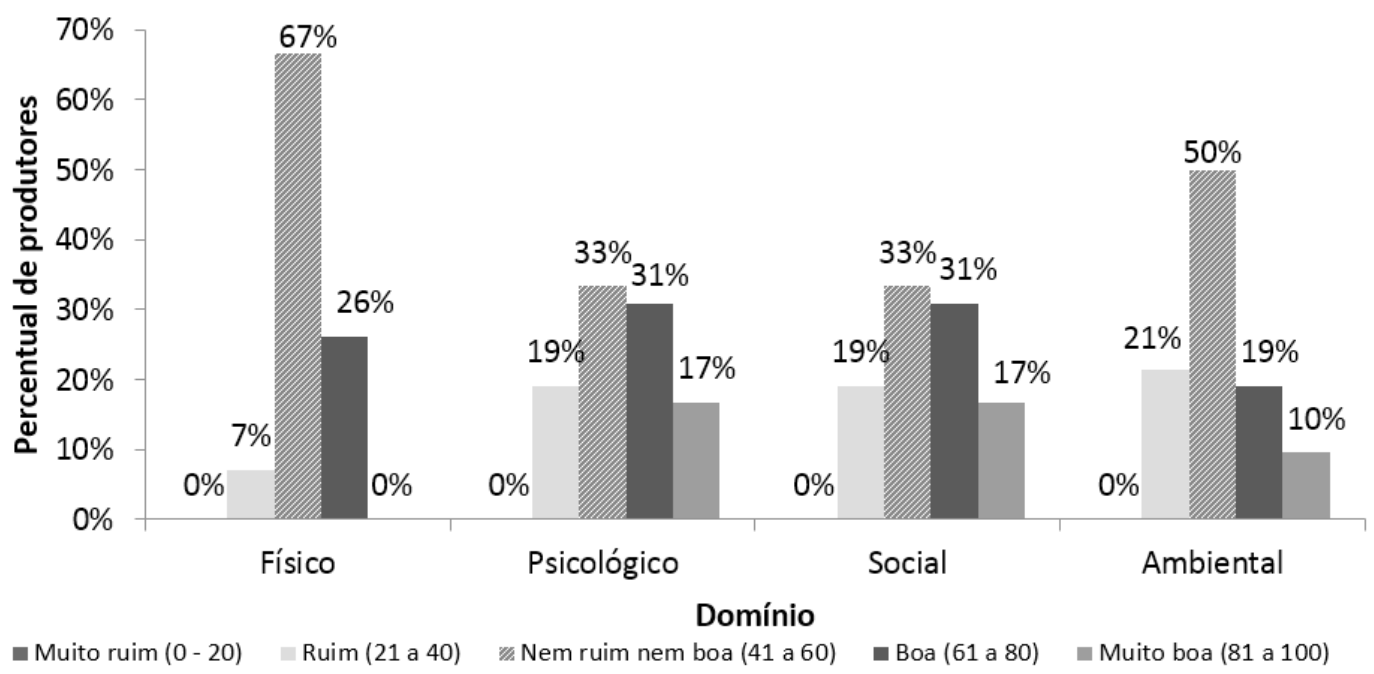

Fonte: Dados da pesquisa (2018)

No domínio psicológico, foi obtido um percentual um tanto equilibrado, no qual $52 \%$ dos produtores estão insatisfeitos, 19\% consideram "ruim" a sua QV e 33\% consideram "nem ruim e nem boa". Fatores como ansiedade, mau humor, desespero, aparência e, até mesmo, fatores do trabalho cotidiano influenciam para essa insatisfação. Nesse item, $48 \%$ dos participantes afırmam que a sua QV esta satisfatória, sendo que $31 \%$ a consideram boa e $17 \%$ consideram a sua QV "muito boa", considerando-se que essa satisfação está mediada por um bom resultado pelo cenário ao qual se encontra. No domínio das relações sociais, o percentual está bem atrelado ao domínio psicológico com os mesmos valores, e a parte social também é favorecida pelo individuo se encontrar bem, concentrado, com pensamentos positivos, com satisfação de imagem e aparência, sem ansiedade e com psicológico positivo. Nesse item, os participantes apresentam percentual de 52\% de insatisfação, sendo 19\% com QV "ruim", 33\% com QV "nem ruim e nem boa". Já os outros $48 \%$, apresentam satisfação em sua QV, sendo que $31 \%$ acham sua QV boa e 17\% acham sua QV "muito boa". 
Qualidade e estilo de vida de produtores de leite em propriedades rurais

de um município do Cone Sul de Rondônia

O domínio ambiental foi o que apresentou menor percentual de satisfação com a sua QV relacionada ao meio ambiente. Dos participantes da pesquisa, $29 \%$ são satisfeitos com o ambiente onde estão inseridos, entretanto que 19\% consideram sua QV "boa" e 10\% acham sua QV "muito boa". Já $71 \%$ se consideram insatisfeitos com o meio ambiente, sendo que, $21 \%$ acham sua QV "ruim" e $50 \%$ acham sua QV "nem ruim e nem boa".

\section{CONCLUSÃO}

Os resultados mostraram que os produtores rurais de leite, mesmo com a rotina de serviços diários, conseguem perceber seu estilo de vida resultando em sua qualidade de vida. Mais de $70 \%$ consideram seu estilo de vida satisfatório, sendo que o componente "atividade física" obteve um melhor resultado com tendência a um comportamento positivo em virtude de suas atividades rotineiras na propriedade rural e o componente "nutrição" não apresentou um resultado satisfatório, levando a uma tendência de comportamento negativo, em que é possível que não consigam realizar, pelo menos, as cinco refeições diárias pelo volume de trabalho e responsabilidades no campo.

Já os resultados da qualidade de vida - QV diagnosticados por meio dos domínios que compõem o WHOQOL-BREF, ocorreu uma tendência de resultados classificados como "nem ruim e nem bom", com exceção ao domínio psicológico. Os domínios físicos e ambientais apresentaram os escores mais baixos, devendo ser observados os locais de trabalho e também as condições para sua execução.

É necessário ampliar o diálogo com estudos nacionais e pesquisas sobre o estilo de vida e a relação com a qualidade de vida no contexto rural brasileiro, havendo a necessidade de assumir outros estudos como referência para subsidiar as pesquisas relacionadas ao âmbito rural e ao trabalhador rural.

\section{REFERÊNCIAS}

CAMPOS, K. C.; PIACENTI, C. A. Agronegócio do leite: cenário atual e perspectivas. In: Congresso da Sociedade Brasileira de Economia, Administração e Sociologia Rural- Sober, 45, Londrina - PR, 2007. Anais... Londrina, 2007. p. 1 - 18.

CARVALHO, G. L. O. de. Uso da Análise Espacial para Avaliação de Indicadores de Qualidade do Leite na Microrregião de Ji-Paraná. 2011. Dissertação (Mestrado Profissional em Ciência e Tecnologia do Leite e Derivados) - Universidade Federal de Juiz de Fora, Juiz de Fora, 2011.

CÔNSOLI, M. A. FAVA NEVES, M. Estratégias para o leite no Brasil. São Paulo: Atlas, 2006.

COSTA, C. K. L; LUCENA, N. M. G; TOMAZ, A. F.; MÁSCULO, F. S. Avaliação ergonômica do trabalhador rural: enfoque nos riscos laborais associados à carga física. Gestão da Produção, Operações e Sistemas, Bauru, n. 2, p. 101-112, abr./jun. 2011.

COSTA, R. G.; QUEIROGA, R. C. R.; PEREIRA, R. A. G. Influência do alimento na produção e qualidade do leite. Revista Brasileira de Zootecnia, Viçosa, v. 38, n. spe, p.307- 321, 2009.

FLECK, M. P. de A. O instrumento de avaliação de qualidade de vida da Organização Mundial da Saúde (WHOQOL-100): características e perspectivas. Ciênc. saúde coletiva, Rio de Janeiro, v. 5, n. 1, p. 33$38,2000$. 
MORÁS, A. P. de B. et al. Qualidade de vida em propiedades rurais produtoras de leite do Vale do Taquari/ RS. In: Fórum Internacional Ecoinovar, 7., 2018, Santa Maria. Anais... Santa Maria: UFSM, 2018. p. 1-7.

NAHAS, M. V. Atividade física, saúde e qualidade de vida: conceitos e sugestões para um estilo de vida ativo. 7.ed. Florianópolis: Ed. do autor, 2017.

NERO, L. A.; VIÇOSA, G. N.; PEREIRA, F.E.V. Qualidade microbiológica do leite determinada por características de produção. Ciência tecnologia de Alimentos, Campinas, v.29, n.2, p.386-390, abr./jun. 2009.

OLIVEIRA, S. A. de. Percepção de pequenos e médios produtores rurais sobre a tecnologia integração Lavoura-Pecuária-Floresta (iLPF) no município de Ipameri - GO. 2016. Dissertação (Mestrado em Saúde Pública) - Faculdade de Saúde Pública, USP, São Paulo, 2016.

OMS. Promoción de la salud. Glossário. Genebra: OMS, 1998.

PADRÃO, M. B.; SENS, Y. A. S. Quality of life of living kidney donors in Brazil: an evaluation by the short form-36 and the WHOQOL-bref questionnaires. Clinical Transplantation, Nova Jersey, v. 23, n. 5, p. 621-627, 2009

SCARPARO, A. L.; AMARO, F. S.; OLIVEIRA, A. B. Caracterização e avaliação antropométrica dos trabalhadores dos restaurantes universitários da Universidade Federal do rio grande do Sul. Rev HCPA, v. 30, n. 3, p. $247-251,2010$.

SEBRAE. Serviço de Apoio às Micro e Pequenas Empresas em Rondônia. Diagnóstico do Agronegócio do Leite e Derivados do Estado de Rondônia. 1.ed. Porto Velho: SEBRAE, 2015.

SHARKEY, B. J. Condicionamento físico e saúde. 4. ed. Porto Alegre: ARTMED,1998.

SCHEIDT, A. S. J. A. Força Competitiva dos Supermercados como Compradores de Produtos Lácteos da Indústria de Rondônia. 2008. Dissertação (Mestrado em Administração) - Universidade Federal de Rondônia, Porto Velho, 2008.

TIMOSSI, L. S. et al. Adaptação do modelo de Walton para avaliação da Qualidade de Vida no Trabalho. Revista da Educação Física, Maringá, v. 20, n. 3, p. 395-405, 2009. 